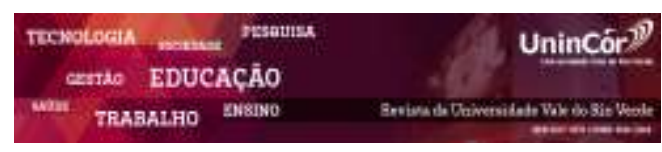

Revista da Universidade Vale do Rio Verde ISSN: 1517-0276 / EISSN: 2236-5362 v. 17 | n. 1 | Ano 2019

João Francisco Selhorst Soares Graduado em Psicologia pela Faculdade de Rolim de Moura - FAROL. joaoselhorst16@hotmail.com

Maria Leticia Marcondes Coelho Oliveira Doutoranda em Psicologia pela Pontifícia Universidade Católica - PUC/RS. marialeticiamcoliveira@hotmail.com

Dayane Fernandes Ferreira

Graduada em Psicologia pela Faculdade de Rolim de Moura - FAROL, Mestre em Educação pela

Universidade Federal de Rondônia - UNIR psicologadayane2015@ hotmail.com

Eraldo Carlos Batista Doutorando em Psicologia Pela Pontifícia Universidade Católica - PUC/RS, Mestre em Psicologia pela Universidade Federal de Rondônia - UNIR e Professor da Faculdade Católica de Rondônia - FCR eraldo.cb@hotmail.com

\section{AS HABILIDADES SOCIAIS COMO FATORES ALIADOS ÀS PRÁTICAS DO PROFESSOR}

\begin{abstract}
RESUMO
O professor está em constante interação com seus alunos no ambiente escolar e desempenha um papel fundamental do processo de transmissão do conhecimento, do desenvolvimento educacional e social do corpo discente. Além disso o professor pode contribuir pelo sucesso ou insucesso que seus alunos terão no decurso do seu desenvolvimento acadêmico e pessoal, por meio de práticas pedagógicas que facilitem a aprendizagem de seus alunos. Este artigo consiste numa revisão de literatura acerca das habilidades sociais e sua relação com o professor, dada sua importância para o mesmo na transmissão de saberes e na interação com seus alunos. Para elaboração do presente artigo, buscaram-se informações concernentes as Habilidades Sociais e o Professor em livros e artigos científicos publicados em banco de dados como SciELO e Pepsic, num período correspondente entre os anos de 1996 e 2009. Os dados obtidos corroboram para o entendimento da importância das habilidades sociais para o professor quanto agente fundamental no processo de transmissão dos saberes e na interação deste com seus alunos.
\end{abstract}

Palavras-chave: Habilidades Sociais. Professor. Alunos.

\section{SOCIAL SKILLS AS FACTORS ALLOCATED TO TEACHER PRACTICES}

\begin{abstract}
The teacher is in constant interaction with his students in the school environment and plays a fundamental role of the transmission process of knowledge, of the educational and social development of the student body. In addition, the teacher can contribute to the success or failure that their students will have in the course of their academic and personal development, through pedagogical practices that facilitate the learning of their students. This article consists of a literature review about social skills and their relationship with the teacher, given its importance to the teacher in the transmission of knowledge and interaction with his students. In order to elaborate the present article, information concerning the Social Skills and the Professor in scientific books and articles published in database such as SciELO and Pepsic, in a corresponding period between the years of 1996 and 2009 were searched. The data obtained corroborate the understanding the importance of social skills for the teacher as a fundamental agent in the process of transmission of knowledge and in the interaction of this with its students.
\end{abstract}

Keywords: Social Skills. Teacher. Students. 


\section{INTRODUÇÂO}

As Habilidades Sociais podem ser observadas nos mais variados contextos e correspondem a classes de comportamentos específicos que um indivíduo emite para completar com sucesso tarefas nas mais variadas situações sociais. De acordo com Gresham (2009), “As habilidades sociais constituem uma classe específica de comportamentos que um indivíduo emite para completar com sucesso uma tarefa social". As habilidades sociais implicarão no modo com a qual um indivíduo interpretará e se comportará em relação às demandas de determinada situação, sobretudo em contextos de interação social.

Existem inúmeras habilidades sociais sabidas, distribuídas em classes de HS de comunicação, HS de civilidade HS assertivas, direito e cidadania, HS empáticas, HS de trabalho e HS de expressão de afeto positivo. Indivíduos que apresentam repertório de habilidades sociais elaborado terão maior capacidade de participar de interações sociais de forma assertiva, configurando competência social. A competência social, então, refere-se ao desempenho adequado do indivíduo em situações sociais, como por exemplo, iniciar e/ou encerrar uma conversação (GRESHAM, 2009). Déficits no repertório de habilidades sociais implicam não só em desempenhos sociais menos adequados, mas também em baixa qualidade de vida e desempenho profissional menos produtivo (DEL PRETTE; DEL PRETTE, 2001).
O professor é o agente facilitador da aquisição do conhecimento de seus educandos. $\mathrm{O}$ mesmo encontra-se em constante interação com seus alunos, e diante disto faz uso de seu repertório de habilidades sociais para cumprir com suas obrigações profissionais. Considera-se que este deverá utilizar-se de seu repertório de habilidades para atender a sua demanda, que corresponde a realizar seu trabalho adequadamente, atendendo também as exigências individuais de seus alunos, prezando por boas interações e um ambiente favorável à educação.

Segundo Meireles (2009), a qualidade do relacionamento do professor para com seus alunos é influenciada diretamente pelo repertório de habilidades sociais do educador. Deste modo, um professor com elaborado repertório de Habilidades Sociais terá maiores chances de se relacionar de modo assertivo e eficaz com seus educandos, além de servir como exemplo de desempenho social adequado a estes.

Este artigo consiste numa revisão de literatura, de abordagem qualitativa e de cunho descritivo, usando para análise dos dados o raciocínio dedutivo. Foram usados como fontes de pesquisa, considerando para critério de inclusão, livros e artigos científicos que discorrem acerca da área de habilidades sociais, bem como produções científicas voltadas ao professor, sua prática docente e questões relacionadas à formação continuada e treinamento de habilidades sociais, excluindo-se do interesse das fontes pesquisadas quaisquer 
outras áreas ou temática que não sejam as aqui citadas. Obteve-se através de pesquisa eletrônica, nos bancos de dados de portais como Scielo e Pepsic, um total de 41 artigos, tendo se utilizado na elaboração deste um total de nove artigos, produzidos num período que compreende entre os anos de 1996 e 2009.A Introdução deve apresentar a delimitação do assunto, objetivos da pesquisa e outros elementos sobre o tema explanado.

O Desenvolvimento, parte principal do texto, apresenta de forma ordenada o assunto tratado. Pode ser dividido em seções e subseções, de acordo com o tema abordado.

As Considerações Finais abordam os resultados da pesquisa de forma a responder às questões apresentadas na introdução.

\section{DAS HABILIDADES SOCIAIS}

A área das habilidades sociais tem despertado crescente interesse em pesquisadores nos últimos anos, sobretudo estudiosos do comportamento. Este interesse aparentemente coincide com o aumento da requisição por desempenhos sociais cada vez mais competentes, e por interações sociais ajustadas e assertivas em diferentes contextos.

Inúmeros autores apontam definições na busca de descrever e "delimitar" as habilidades sociais. Merrell e Gimpel (1998 apud GRESHAM, 2009) elaboram que as habilidades sociais são entendidas como "uma classe de respostas comportamentais, uma vez que comportamentos sociais específicos são agrupados sob a categoria de habilidade social". Segundo Silva (2002), um comportamento socialmente habilidoso corresponde à expressão pelo sujeito, de sentimentos, opiniões e desejos, considerando suas próprias aspirações, respeitando, porém, aos outros sujeitos, sendo que com isto consiga a resolução de problemas imediatos da demanda de uma situação social e também a redução da probabilidade de ocorrência de problemas futuros.

Del Prette e Del Prette (2009) afirmam que as habilidades sociais são aprendidas desde a infância nas interações sociais com familiares, amigos e mesmo no ambiente escolar, são influenciados pelas condições encontradas no ambiente e desenvolvem-se durante toda a vida, possibilitando ao mesmo a capacidade de ter adequado desempenho social em diferentes contextos.

Além disto, os desempenhos sociais do indivíduo gerarão no ambiente em que se encontra consequências importantes para a manutenção ou mudanças nos padrões de comportamento do mesmo. Um exemplo prático de consequência seria um feedback positivo de um indivíduo do ambiente para um indivíduo que apresente um desempenho social habilidoso, o que aumentaria a probabilidade do comportamento adequado tornar a repetir-se futuramente (DEL PRETTE; DEL PRETTE, 2009).

Com relação à utilização do termo habilidades sociais Del Prette e Del Prette (2009) defendem que se utilizado de modo indevido, a definição de habilidade social toma um sentido incompleto e equívoco de que as habilidades sociais são meras "normas" de convivência social, como por exemplo, ser educado e tratar ao outro com etiqueta e delicadeza. 
O termo habilidades sociais, geralmente utilizado no plural, aplica-se às diferentes classes de comportamentos sociais do repertório de um indivíduo, que contribuem para a competência social, favorecendo um relacionamento saudável e produtivo com as demais pessoas (DEL PRETTE; DEL PRETTE, 2009, p. 31).

Tratando-se de habilidades sociais, é comum abordar os conceitos de competência social e desempenho social, e há que se ter cautela para não equivocar-se em considerar tais conceitos como sinônimos. De acordo com Del Prette e Del Prette (2001, p.12), "Qualquer comportamento ou sequência de comportamentos que ocorre em uma situação social é considerado um desempenho social". Já o termo competência social, segundo Del Prette e Del Prette (2009) dizem respeito à capacidade do indivíduo em medir seus pensamentos, sentimentos e ações, em função de seus objetivos e das demandas sociais de modo coerente.

Então, diz-se de outro modo que a competência social corresponde à eficiência do desempenho social de um indivíduo, no modo como o mesmo utiliza seu repertório de habilidades sociais nos contextos de interação social, defendendo seus interesses, mas respeitando ao mesmo tempo os interesses do outro.

Um desempenho social pode sofrer influência de fatores como cultura, situação onde o indivíduo se encontra, e fatores relacionados ao próprio indivíduo. Del Prette e Del Prette (2009, p.32) afirmam que "A cultura, com suas normas e valores, influencia os relacionamentos quando define os padrões de comportamento valorizados ou reprovados para os diferentes tipos de situações, contextos e interlocutores. "As situações que se apresentam e que exigem uma resposta do sujeito são as mais variadas, podendo incluir locais em que os indivíduos se comportam e interagem, como por exemplo, numa loja de roupas, numa festa ou num velório. Segundo Del Prette e Del Prette (2009, p. 32) são fatores da situação que influem no desempenho social " [...] o evento antecedente e consequente para determinados comportamentos sociais e as regras explícitas e implícitas que sinalizam os comportamentos aí valorizados, aceitos ou proibidos".

A respeito da influência dos fatores situacionais, Silva (2002, p.5) afirma que:

\begin{abstract}
A dimensão situacional do comportamento sugere que as pessoas podem se comportar de forma socialmente adequada em um contexto e não em outro; por exemplo, elas podem ser habilidosas em ambientes de trabalho com colegas, autoridades $\mathrm{e}$, no entanto, não generalizarem estas habilidades para $\mathrm{o}$ contexto de educação de filhos. Frente a isto, pode-se perguntar: por que esta generalização não ocorre? Uma explicação possível, à luz da análise do comportamento, seria que, como as pessoas são sensíveis às consequências de seus próprios comportamentos, neste caso, é possível que o comportamento socialmente adequado é mantido no ambiente de trabalho por ser reforçado, o que pode não estar acontecendo no ambiente familiar.
\end{abstract}

Assim, não significa dizer que o indivíduo que possui um elaborado repertório de habilidades sociais terá desempenhos sociais predominantemente positivos ou condizentes com tal repertório em todas as situações sociais que se apresentem.

Com relação a influência do fator pessoal no desempenho social, Del Prette e Del Prette (2009) exemplificam que um indivíduo com baixa autoestima tende a evitar contato 
visual, além de ter problemas de articulação de palavras e fluência de voz em situações que o confrontem, como falar de si mesmo, o que afetará negativamente seu desempenho social.

Para que o comportamento de um indivíduo possa ser considerado socialmente habilidoso, este deve atender coerentemente as demandas que irão surgir por meio das situações sociais. Para isto, o indivíduo necessita aprender a desempenhar comportamentos que são aguardados e estimados socialmente, condizentes as suas características (como sexo e idade), além de lidar com seus fatores pessoais (como por exemplo, objetivos e sentimentos) (DEL PRETTE; DEL PRETTE, 2009).

\section{O PROFESSOR}

O professor é um agente social que tem o papel de transmitir conhecimento, e o desempenho deste servirá aos olhos de seus alunos, especialmente aos que estão nas etapas iniciais do processo de formação escolar, como um modelo de desempenho social a ser seguido. Nesse sentido, o profissional docente é responsável pelo desempenho de socialização, educação e comunicação do ser humano em todo o seu desenvolvimento. Além disso, exerce um papel essencial no desenvolvimento e na construção de profissionais hábeis que, além de desempenhar suas atividades com competência, conhece também os seus direitos (ALMEIDA et al., 2017).

Compete ao professor transmitir saberes das mais variadas áreas. Ou seja, o professor exerce um papel $\mathrm{n}$ a formação do aluno, que não se restringe apenas a passar o conhecimento, pois essa colocação é muito ampla e vaga (BATISTA; LUZ; BRUM, 2015). Pesa sobre o mesmo a responsabilidade de ser referência de conduta para seus alunos, e suas contribuições vão desde a formação acadêmica de seus alunos até a formação de indivíduos socialmente competentes e ajustados. Desde muito cedo ao ingressar na escola e iniciar sua vida acadêmica, a criança está sob os cuidados e ensinamentos de seus professores, que fazem a mediação entre o aluno e os diversos saberes, contribuindo tanto para a formação acadêmica quanto social destes, e isto se estenderá até os mais elevados graus de formação de nível superior nas diversas áreas do conhecimento. Em outras palavras pode-se então concluir que o professor tem um importante papel no desenvolvimento do presente e das futuras gerações, pois dirige os alunos no processo do saber, estimulando seu desenvolvimento pessoal e intelectual (SOARES; OLIVEIRA; BATISTA, 2017).

No ambiente escolar são necessários aspectos favoráveis ao aprendizado e desenvolvimento dos educandos, incluindo uma boa relação entre o professor e seus alunos. Meireles (2009) aponta que uma das prioridades do sistema educativo é o desenvolvimento de habilidades sociais dos alunos na escola, e esta implica numa relação assertiva e eficaz do professor com seus alunos. Ao ingressar na escola, é necessário que a criança encontre um ambiente que favoreça tanto seu desenvolvimento acadêmico quanto social, tendo em vista uma adequada formação para a vida e para o mundo do trabalho. Nesta conjuntura, o professor é incumbido de acompanhar seus alunos, buscando criar condições favoráveis ao 
desenvolvimento e aprendizado de novas habilidades.

Contudo, ao desenvolver suas atividades em sala de aula, o professor precisa estar ciente sobre alguns aspectos da vida dos alunos, como o nível de desenvolvimento cognitivo deles, e se o trabalho pode influenciar ou não a aprendizagem e o convívio sociocultural. O autoconhecimento do professor é o que estimulará o seu desenvolvimento pessoal e profissional (ALMEIDA et al., 2017. Por outro lado, diante de suas atribuições que recaem sobre os professores estão fatores que interferem diretamente no desempenho de sua profissão. Questões ligadas à infraestrutura da instituição escolar, desvalorização profissional, falta de opções para aperfeiçoamento profissional, relacionamento professor-aluno e até mesmo salas de aula superlotadas estão costumeiramente ligadas às dificuldades encontradas por professores em seu ambiente de trabalho, sobretudo no sistema público de ensino.

Rachid e Faria (2009) realizaram um estudo onde analisaram o trabalho de professores do ensino médio e fundamental da rede pública no Estado de São Paulo, considerando as condições de trabalho e como estes avaliam o próprio trabalho. Dentre as constatações alcançadas pelas autoras está a de que os professores estudados apontaram entre outras coisas, em sua maioria, a baixa remuneração salarial e salas de aulas com grande número de estudantes como sendo alguns dos piores fatores relacionados à prática docente.

\section{AS HABILIDADES SOCIAIS E O PROFESSOR}

A importância de avaliar o repertório de habilidades sociais se justifica amplamente dada sua relação com a saúde, a satisfação pessoal, a realização profissional e a qualidade de vida (DEL PRETTE; DEL PRETTE, 2001). Segundo Nyarady e Boas (2004) as habilidades sociais estão ligadas à qualidade dos relacionamentos interpessoais, além de relacionar-se com o desempenho de atividades laborais, sobretudo em termos de produtividade, bem como a saúde e qualidade de vida e realização profissional, fator que tem contribuído para o crescente interesse no estudo do tema.

São vários os itens que compõem um repertório de habilidades sociais elaborado, e dentre eles está a assertividade. Del Prette e Del Prette (2001) apontam a assertividade como o modo com a qual o indivíduo expressa seus sentimentos e exerce seus direitos de modo coerente e sem atingir ou ferir os direitos do outro. Esta ainda pode ser característica de situações de enfrentamento, pois envolve risco de consequências aversivas por parte do outro.

As principais classes e subclasses de habilidades sociais foram elaboradas e organizadas em seis itens, sendo estes apresentados respectivamente como:

HS de comunicação: fazer e responder perguntas, pedir feedback, gratificar/elogiar, dar feedback, iniciar, manter e encerrar conversação;

HS de civilidade: dizer por favor, agradecer, apresentar-se, cumprimentar, despedir-se;

HS assertivas, direito e cidadania: manifestar opinião, concordar, discordar, fazer, aceitar e recusar pedidos, desculpar-se, admitir falhas, interagir com autoridade, estabelecer relacionamento afetivo/ou sexual, encerrar relacionamento, expressar 
raiva/desagrado, pedir mudança de comportamento e lidar com críticas;

HS empáticas: parafrasear, refletir sentimentos, expressar apoio;

HS de trabalho: coordenar grupo, falar em público, resolver problema, tomar decisões e mediar conflitos, habilidades sociais educativas;

HS de expressão de afeto positivo: fazer amizade, expressar a solidariedade, cultivar o amor. (DEL PRETTE; DEL PRETTE, 2001, p. 13, grifo do autor).

Observando os itens supracitados e considerando o ofício de professor, é possível realizar o apontamento de algumas características esperadas num repertório de habilidades sociais de um profissional desta área, sabendo que este se encontra em constante interação social no exercício de sua função, como por exemplo, fazer e responder perguntas, gratificar/elogiar, dar feedback, expressar apoio, coordenar grupos, falar em público, etc.

Espera-se que o professor disponha de um elaborado repertório de habilidades sociais para que tenha um desempenho social adequado, transmitindo conhecimento de modo eficaz, aliando as técnicas educativas ao modo com a qual percebe seus alunos e suas respectivas necessidades, fazendo adequações a realidade de seus educandos e trabalhando com seu real potencial, favorecendo com isto um processo educativo eficiente.

Considerando a importância de interações educativas em sala de aula, para uma efetiva construção social do conhecimento e ressaltando o papel do professor enquanto participante, condutor e mediador dessas interações, defende-se que a competência profissional do professor requer também um repertório altamente diferenciado de habilidades interpessoais que inclui, entre outros aspectos, a percepção das demandas imediatas do contexto escolar, flexibilidade para mudanças na atuação, de acordo com essas demandas, bem como habilidade de produzir conflitos sócio-cognitivos entre os alunos e reagir positivamente às tentativas de solução destes conflitos por parte dos mesmos (PONTES; TORRES, 1996).

Espera-se então, que o professor possua bom repertório de habilidades sociais educativas. Como discorrem Del Prette e Del Prette (2008), as habilidades sociais educativas estão voltadas à promoção do aprendizado e desenvolvimento, podendo constituir em mudança no repertório comportamental do educando.

O professor é responsável pela construção do conhecimento, sendo ao mesmo tempo um facilitador das potencialidades humanas. É ele quem introduz o indivíduo no universo intelectual, e é capaz de despertar neste a ânsia pelo conhecimento. (COLL; COLOMINA, 1996; DEL PRETTE et al., 1998; apud SOARES et al., 2009).

Peça crucial no processo de educação, o professor necessita ser socialmente competente visto que sua desenvoltura social em sala de aula contribuirá para o processo de aprendizagem de seus alunos. Neste sentido, o aluno refletirá o que o professor apresenta em sala de aula, pelo modo como o docente reconhece a demanda de seu aluno e através disto desenvolve seu trabalho, controlando o ritmo e a quantidade de conteúdos que irá transmitir, realizando questionamentos bem como respondendo a estes de modo assertivo, criando um ambiente em que envolverá o aluno em seu próprio processo de aprendizagem (PERRENOUD, 2001 apud SOARES et al., 2009, p. 37).

Soares et al. (2009) a esse respeito, defendem que o professor exerce uma atividade essencialmente relacional cuja qualidade das interações exercidas se reflete no desenvolvimento de competências sociais e 
acadêmicas de seus alunos. Por este motivo, Meirelles (2008 apud SOARES et al., 2009) diz que a identificação das habilidades sociais dos professores se faz necessária no sentido de que estes interajam de modo mais eficaz com seus alunos, de acordo com as particularidades de cada um, para que estes tenham um positivo desenvolvimento tanto social quanto acadêmico.

Deste modo, um professor com elaborado repertório de habilidades sociais terá interações sociais mais eficazes com seus alunos, tendo maior sucesso em motivá-los, e de reconhecer e trabalhar com as dificuldades e/ou potencialidades individuais de cada estudante, para que este amplie suas capacidades e tenha sucesso no curso de sua formação acadêmica e desenvolvimento social. Dessa forma, pode-se inferir que a qualidade do desenvolvimento crítico do aluno está, entre outros fatores, atrelada às condições que favorecem o desenvolvimento dos seus aspectos criativos (BATISTA; NASCIMENTO. 2015).

As expectativas do professor para com seus alunos podem influenciar no desempenho dos mesmos. $\mathrm{O}$ professor que valoriza as características positivas de seus educandos contribui para que estes tornem estas características ainda mais acentuadas, enquanto o aluno que se sente resignado tem a tendência em confirmar aspectos negativos, o que influirá em seu desenvolvimento (SOARES et al., 2009).

Entretanto, o fato de o professor possuir um elaborado repertório de habilidades sociais não implica que este se portará de modo habilidoso em todas as situações, dada a influência da dimensão situacional no comportamento. Caso o professor não apresente desempenhos sociais condizentes com sua prática profissional, o mesmo poderá ter lacunas no exercício de seu ofício, o que possivelmente afetará a seus educandos, já que o professor poderá deixar de atender adequadamente as demandas dos mesmos.

Neste sentido são adotadas medidas voltadas ao desenvolvimento e/ou aperfeiçoamento de habilidades sociais do professor através de programas de formação continuada, melhorando assim sua interação com seus educandos. Meireles (2009) elabora que há preocupação em se desenvolver habilidades sociais de professores objetivando que este tenha competência em idealizar e dirigir, participar e realizar a mediação de interações educativas para seus alunos em sala de aula.

A formação continuada de professores tem sido entendida como um processo permanente de aperfeiçoamento dos saberes necessários à atividade profissional, realizado após a formação inicial, com o objetivo de assegurar um ensino de melhor qualidade aos educandos (CHIMENTÃO, 2009, p. 3).

Para intervenção neste contexto tem se recorrido ao Programa de Desenvolvimento de Habilidades Sociais na Formação Continuada do Professor - PRODIP. O PRODIP corrobora para que o professor aprimore a interação com seus alunos, propiciando ao docente, sensibilidade em observar atentamente e verificar o desempenho destes, tornando-se mais flexível e melhorando as condições de ensino oferecidas ao aluno (MEIRELES, 2009).

Há também o emprego do Treinamento de Habilidades Sociais - THS, cujo objetivo é o de desenvolver e/ou aprimorar habilidades de um sujeito por meio de situações estruturadas que simulam interações sociais. 
Del Prette e Del Prette (2006) descrevem o THS como:

[...] uma atividade de grupo, estruturada de modo análogo ou simbólico a situações cotidianas, que cria oportunidade para desempenhos específicos, permitindo que o facilitador avalie os comportamentos observados e utilize as contingências pertinentes para fortalecer e/ou ampliar o repertório de habilidades sociais dos participantes (DEL PRETTE; DEL PRETTE, 2006, p. 03).

A necessidade de se promover o desenvolvimento e aperfeiçoar um repertório de habilidades fundamentais as relações sociais se explica dada sua grande importância, já que o déficit das mesmas poderá acarretar em interferência no desempenho e na eficiência de relações sociais educativas (NYARADY; BOAS, 2004). Dessa maneira, Almeida et al. (2017) afirmam que o professor vai além de proporcionar conhecimento específico, ele tem a responsabilidade de estimular o desenvolvimento social dos alunos para que estes possam melhorar as suas habilidades de comunicação e de entrosamento em sala de aula, o que promoverá também o seu

\section{CONSIDERAÇÕES FINAIS}

As habilidades sociais são fundamentais para as interações sociais. Numa interação social há a incidência de fatores que irão exigir do indivíduo a habilidade de comportar-se de modos variados. Neste sentido, as habilidades sociais darão ao sujeito a destreza de identificar a situação que se apresenta e adequar seus comportamentos para que estejam em harmonia com a mesma.
Como aludido, o sujeito socialmente habilidoso age com coerência nas situações de interação social, pois consegue identificar as demandas do outro, agindo de modo a atender tais demandas sem que deixe de considerar as próprias. Além de contribuir para relações interpessoais saudáveis e harmoniosas, as habilidades sociais implicam em sucesso profissional e qualidade de vida. Em todos os contextos onde há interação entre sujeitos podem ser observadas tais habilidades, incluindo no contexto escolar, considerando ainda as interações entre o professor e seus alunos.

Dada a importância do professor em transmitir os mais diversos saberes, além de ser modelo de comportamento socialmente competente e de contribuir para a formação acadêmica e social de seus educandos, espera-se que o mesmo apresente um elaborado repertório de habilidades sociais, sobretudo habilidades sociais educativas, afim de que possa ir além da pura transmissão de saberes, tendo sensibilidade para perceber as minúcias que envolvem este processo, atentando para as necessidades tanto em âmbito coletivo como individual de seus alunos e realizando adequações em seus métodos em prol destes, a fim de desenvolver seu trabalho eficazmente atendendo ao mesmo tempo as necessidades de seus alunos.

Deste modo, quanto mais desenvolvido for o repertório de habilidades sociais do professor, maior eficácia terá seu desempenho profissional, e consequentemente maiores serão os ganhos de seus alunos que terão suas necessidades abarcadas. Do contrário, o professor apresentará falhas no atuar de seu ofício, o que afetará também seus alunos. Neste 
caso, considerar-se-á a necessidade de realizar intervenção voltada ao aperfeiçoamento e/ou desenvolvimento de habilidades sociais, como o PRODIP ou THS, proporcionando ganhos que vão desde a aquisição de novas habilidades educativas até mesmo ao aperfeiçoamento de habilidades tão comumente utilizadas pelo professor em sala de aula.

\section{REFERÊNCIAS}

ALMEIDA, K. C. C. et al. Habilidades sociais de professores de uma escola estadual de ensino fundamental do interior de Rondônia. Unoesc \& Ciência-ACHS, v. 8, n. 1, p. 71-80, 2017.

Disponível em:

<https://portalperiodicos.unoesc.edu.br/achs/arti cle/view/10981>. Acesso em: 16 abr. 2018.

BATISTA, E. C.; LUZ, E. N.; BRUM, A. L. O. Autopercepção sobre as práticas docentes para o desenvolvimento da criatividade em uma instituição de ensino superior da Amazônia. Revista Intersaberes, v. 10, n. 21, p. 595-612, 2015.Disponível em:

<https://www.uninter.com/intersaberes/index.ph p/revista/article/view/769/505>. Acesso em 23 set. 2018.

BATISTA, E. C.; NASCIMENTO, A. B. Percepção de acadêmicos quanto ao estímulo à criatividade por parte de seus professores. Revista Brasileira de Ensino Superior, v. 1, n. 2, p. 54-63, 2015. Disponível em:

<https://seer.imed.edu.br/index.php/REBES/artic le/view/1007>. Acesso em: 21 nov. 2018.

CHIMENTÃO, L. K. O significado da formação continuada docente. In: CONGRESSO NORTE PARANAENSES DE EDUCAÇÃO FÍSICA ESCOLAR. 2009.Disponível em:

<http://www.uel.br/eventos/conpef/conpef4/trab alhos/comunicacaooralartigo/artigocomoral2. pdf> Acesso em: 25 out. 2016.

DEL PRETTE, A.; DEL PRETTE, Z.A.P. Um sistema de categorias de habilidades sociais educativas. São Carlos, SP: Paidéia, v. 18, n. 41, p. 517-530, 2008. Disponível em: <http://www.scielo.br/pdf/paideia/v18n41/v18n4 1a08>. Acesso em: 04 out. 2016.

DEL PRETTE, A.; DEL PRETTE, Z.

Habilidades sociais: conceitos e campo teóricoprático. [S.I]: Texto online, 2006. Disponível em:

$<$ http://www.rihs.ufscar.br/armazenagem/pdf/arti gos/habilidades-sociais-conceitos-e-campoteorico-pratico>. Acesso em: 17 mar. 2016.

DEL PRETTE, A; DEL PRETTE, Z. Inventário de habilidades sociais: manual de aplicação, apuração e interpretação. São Paulo: Casa do Psicólogo, 2001.

DEL PRETTE, A; DEL PRETTE, Z. Psicologia das habilidades sociais na infância: teoria e prática. 4. ed. Petrópolis, RJ: Vozes, 2009.

GRESHAM, F. Análise do comportamento aplicada às habilidades sociais. In: DEL PRETTE, A.; DEL PRETTE, Z. (Org.). Psicologia das habilidades sociais. Petrópolis, RJ: Vozes, 2009. p. 17-66.

MEIRELES, R.M. As relações entre as medidas de habilidades sociais do professor do ensino fundamental II e seu desempenho social em Sala de aula. Revista Visões. 6. ed. n.6, v.1, p.1-28, 2009. Disponível em: <http://www.fsma.edu.br/visoes/ed06/Edicao_6_ artigo_3.pdf> Acesso em: 12 set. 2016.

NYARADI, N.O.; BOAS, A. Habilidades sociais e competências sociais exigidas do professorlíder. Rio de Janeiro: UFRJ, 2004. p. 1-14. Disponível em:

<http://repositorio.ufsc.br/handle/123456789/35 783> Acesso em: 17 mar. 2016.

PONTES, A. C.; TORRES, A. C. Efeitos de uma intervenção sobre a topografia das habilidades sociais de professores. Psicologia Escolar e Educacional, v. 2, n. 1, p. 11-22, 1998.

Disponível em:

<http://www.scielo.br/pdf/pee/v2n1/v2n1a02.pdf $>$ Acesso em: 10 mar. 2016.

RACHID, A. FARIA, G. A dor e a delícia de ser professor: uma análise do trabalho na rede estadual de ensino de São Paulo. Curitiba: UniBrasil. Cadernos da Escola de Negócios. n. 7, p. 1-17, 2009. Disponível em: $<$ http://apps.unibrasil.com.br/revista/index.php/n 
egociosonline/article/viewFile/290/225> Acesso em: 04 out. 2016.

BOLSONI-SILVA, A. T. Habilidades sociais: breve análise da teoria e da prática à luz da análise do comportamento. Interação em psicologia, v. 6, n. 2, 2002. Disponível em: $<$ http://ojs.c3sl.ufpr.br/ojs2/index.php/psicologia /article/view/3311> Acesso em: 10 maio 2016.

SOARES, A. B. et al. Estudo comparativo de habilidades sociais e variáveis sociodemográficas de professores. Revista Psicologia-Teoria e Prática, v. 11, n. 1, 2009.Disponível em: $<$ http://editorarevistas.mackenzie.br/index.php/pt p/article/view/893>. Acesso em: 10 mar. 2016.

SOARES, M. M.; OLIVEIRA, T. G. D.;

BATISTA, E. C. O uso de antidepressivos por professores. Revista de Educação do Vale do São Francisco, v. 7, n. 12, 2017. Disponível em: $<$ http://periodicos.univasf.edu.br/index.php/revas f/article/view/25>. Acesso em: 17 maio 2018.

\section{João Francisco Selhorst Soares}

Graduado em Psicologia pela Faculdade de Rolim de Moura - FAROL

Maria Leticia Marcondes Coelho Oliveira
Doutoranda em Psicologia pela Pontifícia
Universidade Católica - PUC/RS

\section{Dayane Fernandes Ferreira}

Graduada em Psicologia pela Faculdade de Rolim de Moura - FAROL, Mestre em Educação pela Universidade Federal de Rondônia - UNIR

\section{Eraldo Carlos Batista}

Doutorando em Psicologia Pela Pontifícia Universidade Católica - PUC/RS, Mestre em Psicologia pela Universidade Federal de Rondônia UNIR e Professor da Faculdade Católica de Rondônia - FCR. 